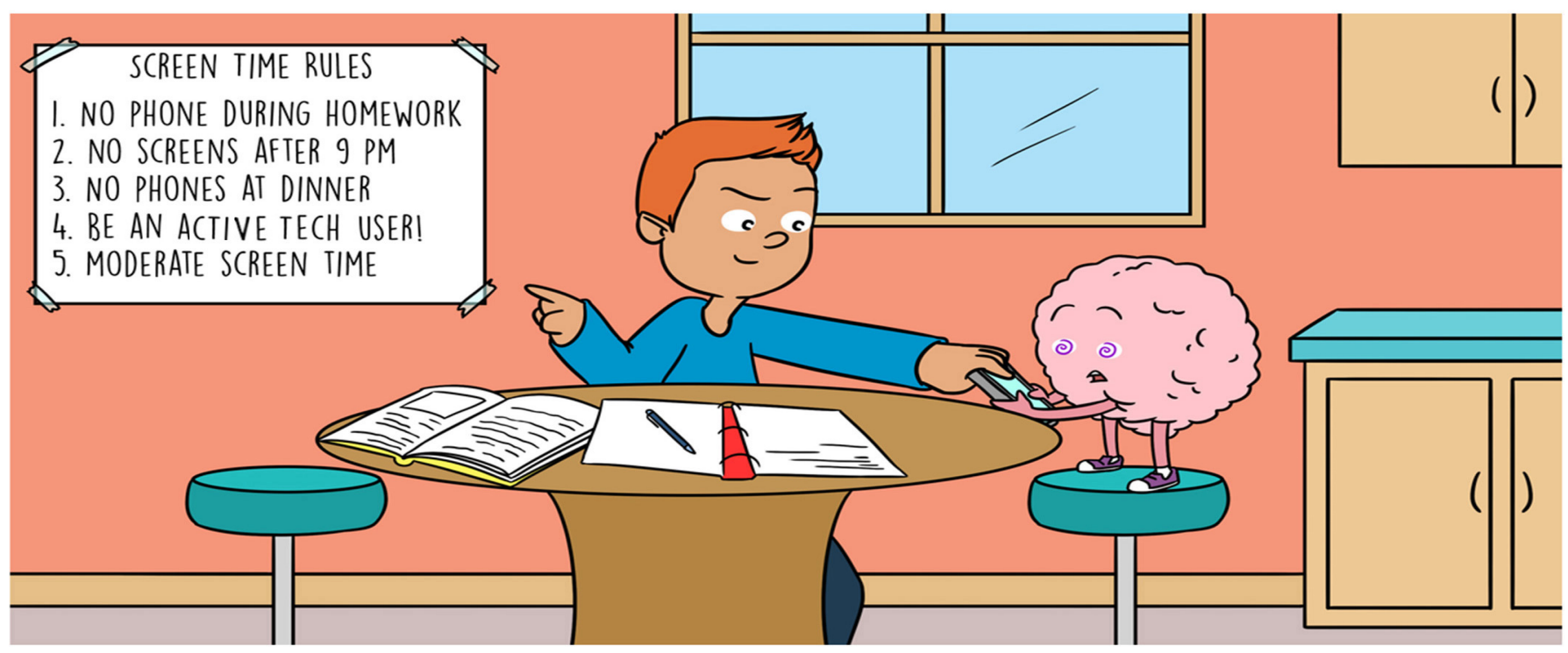

\title{
MIND GAMES: TECHNOLOGY AND THE DEVELOPING TEENAGE BRAIN
}

\section{Lucía Magis-Weinberg * and Estelle L. Berger}

Adolescent Research Collaborative, Institute of Human Development, University of California, Berkeley, Berkeley, CA, United States

YOUNG REVIEWER:

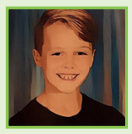

SCOTTY

AGE: 10
The brain has regions that react to things that are exciting or rewarding, and regions that help you plan and control your impulses. Both systems work together to help you learn. As children and teens develop and their brains change, the balance between the reward regions and control regions changes. These brain changes make children and teens more willing to explore, take risks, and learn from friends. However, these brain changes also make it hard for kids to regulate their behavior, especially when friends are around or when there is a lot of excitement. Technology can enhance learning by tapping into the balance between reward and control. However, some technological features can also promote unhealthy social interactions or make it very hard to control impulses online. In this article, we show how the control and reward areas of your brain influence learning. We also discuss how understanding how your brain works can help promote positive learning and empower you to make your own decisions about how to spend time online. 


\section{TEENAGERS GROW UP ONLINE AND OFFLINE}

When it comes to technology, children and teens are the ultimate experts. Ninety-five percent of teenagers between the ages of 13 and 17 in the United States have a smartphone, and 94\% report that they use the Internet at least once a day [1]. As children grow older and become teenagers (or adolescents), they start to gain independence and begin using-and owning-devices, especially as they move into secondary school [2]. Technology provides many opportunities to connect, learn, and have fun, inside and outside the classroom. But technology also carries risks, such as distraction from other activities and relationships, too much screen time, or hasty posting. Both the positive and negative aspects of technology can be amplified by some key features of the developing teenage brain.

\section{THE IMPACT OF TECHNOLOGY DEPENDS ON THE QUALITY OF ONLINE ACTIVITIES}

Research on technology use is difficult for a few key reasons: (1) it is hard for people to accurately report on how much media they use; (2) it is difficult to know whether technology use causes kids to get bad grades and feel upset, or if kids who are already getting bad grades and feeling upset tend to use more technology; and (3) we need to wait until users grow older to measure long-term effects. Despite these challenges, this research is important, and we will share with you what we do know about the links between time online and well-being.

Researchers are finding that using technology in moderation is key (Figure 1): people who spend too little or too much time using digital devices experience the most problems [3]. However, spending a moderate amount of high-quality time on digital devices might be associated with positive experiences, such as feeling happy and connected to friends. High-quality activities are those that require you to be actively engaged, such as chatting with friends and family, working on a project, creating content, or learning through videos. Low-quality activities are associated with feelings of depression, envy and loneliness, and might include scrolling passively, comparing yourself to others on social media, or using your devices late into the night or when you need to finish other tasks. Also, it is important to use technology purposefully and avoid multitasking and distraction. For example, if you do homework while chatting with friends, the quality of both activities is affected. While we want to know the effect on adults as well, the fact that kids are still developing makes children and teenagers particularly exposed to certain potentially negative features of technology (See Box 1). 


\section{Figure 1}

Moderate use of screens (computers, tablets, videogames, and smartphones) is associated with the highest well-being, while both extremes, low and high use, are associated with lower well-being (figure adapted from Przybylski and Weinstein [3]).

\section{ADOLESCENCE}

Period of development between childhood and adulthood; also known as the teenage years (roughly between 10 and 24 years of age).

\section{SOCIO-EMOTIONAL} DEVELOPMENT

The ability to understand, express, and manage emotions and feelings in order to build and maintain relationships with others.

\section{COGNITIVE CONTROL}

Mental processes like attention, memory, and decision making that guide thoughts and behaviors to help us achieve our goals.

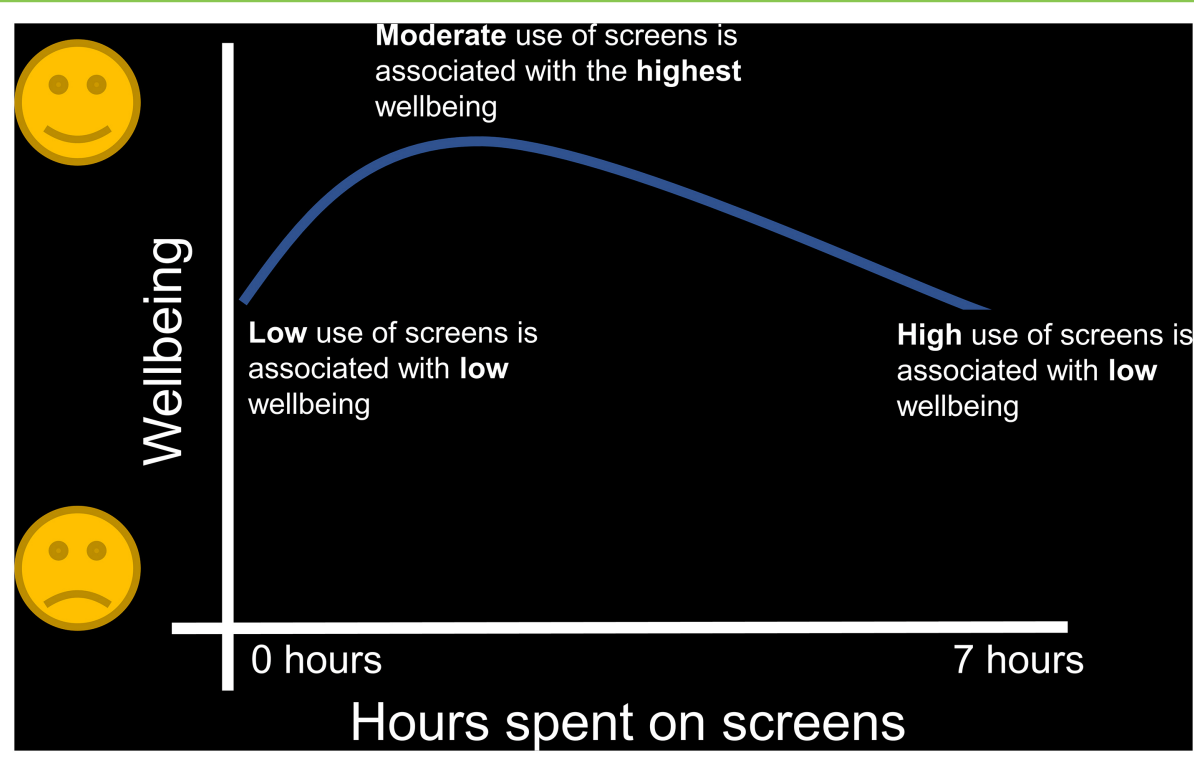

Figure 1

Box 1 | Tech Tips for Teens

1. Pay attention to the quality and content of what you do online instead of total screen time

2. Use technology actively (creating videos, writing stories, chatting with friends and family, using videos to learn a new skills) instead of passively (like scrolling through a celebrity's account)

3. Avoid multitasking: when you are doing homework, turn off your phone

4. Make sure that using your devices is not taking time away from exercise, getting enough sleep, doing homework and interacting with friends and family

5. When you go to sleep, keep your device outside of your bedroom: use an alarm clock instead

6. Turn off all the defaults in apps that might make it hard to control their use, like video autoplay and notifications

7. Take responsibility for your own engagement with digital media, and create a technology use contract that makes sense for you and your family

\section{SOCIAL MEDIA AND THE SOCIAL BRAIN}

The teenage years (adolescence) are a period during which kids are learning a lot both inside and outside the classroom, exploring their interests, and figuring out who they are and how they feel about themselves [4]. Between the ages of 10 and 24, there are big changes in the body and the brain. During these years, we become particularly sensitive to what is happening around us, because our brain networks that control socio-emotional development (Figure 2, in blue and green) are socio-emotional maturing faster than our cognitive control network (Figure 2, in red). The cognitive control network is in charge of mental processes like attention, memory, and decision-making that guide thoughts and behaviors to help us achieve our goals. This means that our capacity to make decisions and learn is affected by how exciting or social the situation is $[2,5]$. 
Figure 2

Brain areas that participate in cognitive control, social processing and reward processing are shown from different angles.

(A) Surface of the right half of the brain, showing regions that are involved in cognitive control and regions involved in social processing. (B) Middle surface of the left side of the brain (the right side has been removed), showing key areas of the social brain. (C) Middle of the brain (imagine that the person is facing you and a slice has been cut), showing regions that are involved in processing rewards.

\section{DEVELOPMENTAL GOALS}

Set of abilities that people are typically expected to achieve during a period of life (like learning to walk, for children, or becoming more independent from parents, for adolescents).

\section{EXTRINSIC} REWARDS

Doing something for external motivation, like getting points, likes, money,

or encouragement.

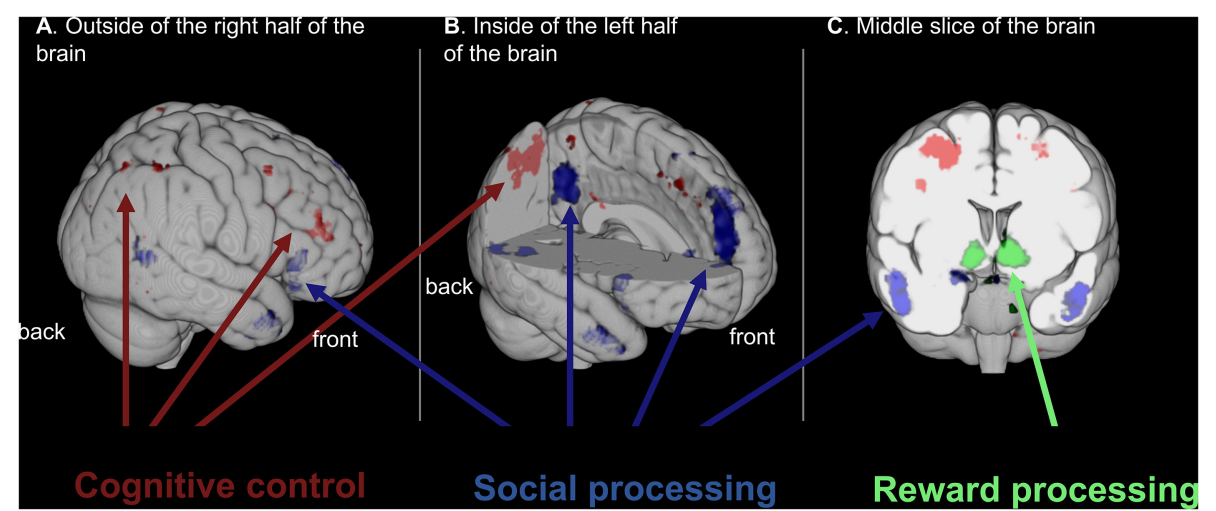

Figure 2

Teenagers have very important socio-emotional developmental goals - like discovering who they are and developing relationships with others-which might be influenced by social media. Teenagers are prone to pay a lot of attention to the number of likes or follows on social media because it feels especially important to be liked by peers and to feel popular and admired during this time $[4,5]$. This need to get extrinsic rewards, specifically positive feedback from friends, might be one of the reasons why the majority of adolescents use social media constantly [6]. Social media can be a great tool to connect with friends when used in a positive way (like learning more about what a friend likes or giving them encouragement). Another key positive aspect of social media is that it creates opportunities to develop many identities: who you are as a student, friend, sibling, or fan of your favorite band [2]. This exploration will help you understand who you are, what and who you like.

However, the desire to be popular might also drive the need to post about risky activities, make mean comments, or send revealing pictures to get attention. Digital drama, cyberbullying, and exposure to inappropriate material can also make adolescents stressed or upset and may harm a person's reputation. When emotions are running high, it is particularly challenging to make good decisions, since cognitive control abilities are still maturing (Figure 2) [4, 5]. Therefore, as you craft a response to a friend who hurt your feelings or consider which picture to post, take an extra moment to cool off and think about whether your future self will regret or benefit from this permanent trace of your opinions and behavior. Drama can really distract from your well-being and your school experience, so consider which social media strategies work best for you.

Some features of social media, such as the fact that you can like, share, and openly comment on posts, can make people do things to get extra attention, impress a virtual audience, and compare themselves with others. In our research, we have found that adolescents in middle 
school who compare themselves with others and seek feedback through social media also reported more depressive and anxious symptoms. In addition, spending a lot of time scrolling through the feeds of others can affect a person's self-esteem. However, one question researchers are trying to answer is whether online activities cause problems or whether people who already have these problems tend to use social media in ways that might be harmful. Keeping these socio-emotional changes in mind, how can you use technology to make your friendships stronger and avoid the social pitfalls of devices?

\section{GETTING "HOOKED" ON DEVICES}

When you are having fun online, it can be especially difficult to monitor your time and you may find yourself "hooked" on your devices-spending much more time online than is good for you. It can even feel that you cannot control how much time or attention you want to give your device. Although the maturation of the cognitive control network (Figure 2, in red) allows you to pay attention for longer periods and avoid distractions, there are limits to your ability to self-regulate, especially in exciting or emotional moments. Remember, during adolescence there is also a surge in activity in regions of the brain that respond to all kinds of rewards, including social rewards (Figure 2, in green). Some rewarding activities can be beneficial to you, such as making friends or getting good grades. Then again, other activities that activate your reward centers can also be bad for you, like eating sugary treats, playing videogames all night, or taking part in dangerous activities. Being more sensitive to rewards makes teens more likely to try out new things, explore, and act in ways that will make them feel good immediately [4]. When you are online, this need to experience immediate rewards might then override your ability to control and think about the long-term future. Gaming, chatting, or streaming late at night might make you feel good in the moment, but be mindful of the consequences the next morning when you are tired and cranky in school (See Box 1).

\section{EFFECTS OF TECHNOLOGY ON SLEEP}

What is the last thing you did before closing your eyes last night? You probably replied to one last text message or fell asleep while watching a show you were streaming. We know that technology use affects sleep, which in turn impacts your brain, body, and health. This has negative effects on your ability to pay attention, learn, and remember. Lack of sleep can also make you feel anxious or sad. Using your devices in bed at night makes it harder for you to go to sleep and is probably making you stay up later than you should. Notifications can also wake you up in the middle of the night! It is very important that your technology use does not interfere with healthy sleep habits, 
particularly at a time when your brain and body are developing. It is a good idea to keep your devices outside your room when you go to bed (See Box 1).

\section{TAKE BACK CONTROL!}

Luckily, we know of some useful skills that can help you to disengage from social media, games, and videos and take back control of your valuable time. If you enjoy watching videos online, turn off "auto-play," which is often the default setting on many platforms. This will make it easier for you to choose when to stop watching. Before you activate a new account, ensure that your profile is protected and deactivate push notifications. Oftentimes, default settings might be designed to keep you hooked, because companies are competing for your attention and time. Take control by choosing settings that help you to use technology in a way that feels right for you. You can also consider leaving your device outside your room at night, or perhaps turn WiFi off completely while you are doing your homework, to avoid temptation and distraction. You can even set reminders on your phone to take breaks and do different activities, like playing sports or spending time with friends and family (See Box 1).

Given what you now know about how your brain responds to social media, computer games, online videos, and other forms of digital media, think about an after-school and weekend schedule that allows you to maintain control of how you spend your time. You know which afternoons you have after-school commitments and the number of hours it takes to do your nightly homework. You also know that it feels important to stay connected to your friends via social media, to post to your channel, and to play your favorite online games. By creating your own guidelines for technology use, presenting them to your parents or teachers, and then benefitting from rules that you have created for yourself, you will be motivated by intrinsic reward. Put simply, an intrinsic reward is that sense of pride or fulfillment that you experience when you have completed something meaningful to you. A system that you design yourself, in collaboration with the adults that care for you, might work better than one that is imposed upon you. Maybe even create a technology use contract with your entire family. Parents struggle with how to manage their devices too, so you can share what you know about how to maintain a healthy digital media balance.

\section{MAKING THE MOST OF TECHNOLOGY}

The teenage years are an exciting time when you will figure out who you are, make sense of what and who you like, and develop the tools you need to pursue your passions. Using your devices purposefully and with intention can help you succeed. There might even be positive mental health benefits to chatting with your friends, posting pictures of your creative work, or connecting with a group of people who share a common interest. Monitor the quality and content of what 
you do online rather than fixate on the number of hours. When using technology, be active rather than passive, and avoid multitasking in order to make the most of your time. Make sure that using your devices is not taking time away from exercising, getting enough sleep, doing your homework, or interacting with your friends and family. While scientists continue to research technology use and the developing brain, it is very important that you take responsibility for your own engagement with digital media. Be in charge of your device, instead of letting your devices be in charge of you.

\section{ACKNOWLEDGMENTS}

We would like to wholeheartedly thank those who assisted in the translation of the articles in this Collection to make them more accessible to kids outside English-speaking countries, and for the Jacobs Foundation for providing the funds necessary to translate the articles. For this article, we would especially like to thank Nienke van Atteveldt and Sabine Peters for the Dutch translation.

\section{REFERENCES}

1. Pew Research Center. 2018. Teens, Social Media \& Technology 2018. Available online at: https: / /www . pewinternet .org/2018/05/31/teens-socialmedia-technology-2018/

2. Moreno, M. A., and Uhls, Y. T. 2019. Applying an affordances approach and a developmental lens to approach adolescent social media use. Digit. Health. 5:2055207619826678. doi: 10.1177/2055207619826678

3. Przybylski, A., and Weinstein, N. 2017. A large-scale test of the Goldilocks hypothesis: quantifying the relations between digital-screen use and the mental well-being of adolescents. Psychol. Sci.

28:204-15. doi: 10.1177/0956797616678438

4. Dahl, R. E., Allen, N. B., Wilbrecht, L., and Suleiman, A. B. 2018. Importance of investing in adolescence from a developmental science perspective. Nature. 554:441-50. doi: 10.1038/nature25770

5. Mills, K. L., Goddings, A. L., and Blakemore, S. J. 2014. Drama in the teenage brain. Front. Young Minds 2:16. doi: 10.3389/frym.2014.00016

6. Rideout, V., and Robb, M. B. 2018. Social Media, Social Life: Teens Reveal Their Experiences. San Francisco, CA: Common Sense Media.

SUBMITTED: 01 October 2019; ACCEPTED: 18 May 2020; PUBLISHED ONLINE: 19 June 2020.

EDITED BY: Sabine Peters, Leiden University, Netherlands

CITATION: Magis-Weinberg L and Berger EL (2020) Mind Games: Technology and the Developing Teenage Brain. Front. Young Minds 8:76. doi: 10.3389/frym.2020. 00076 
CONFLICT OF INTEREST: The authors declare that the research was conducted in the absence of any commercial or financial relationships that could be construed as a potential conflict of interest.

COPYRIGHT () 2020 Magis-Weinberg and Berger. This is an open-access article distributed under the terms of the Creative Commons Attribution License (CC BY). The use, distribution or reproduction in other forums is permitted, provided the original author(s) and the copyright owner(s) are credited and that the original publication in this journal is cited, in accordance with accepted academic practice. No use, distribution or reproduction is permitted which does not comply with these terms.

\section{YOUNG REVIEWER}

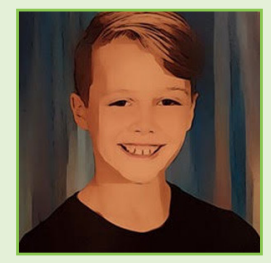

\section{SCOTTY, AGE: 10}

My favorite color is red. My favorite movies are Space Jam and the Goonies. My favorite thing to do in my free time is play sports and video games. My favorite sports are basketball and football.
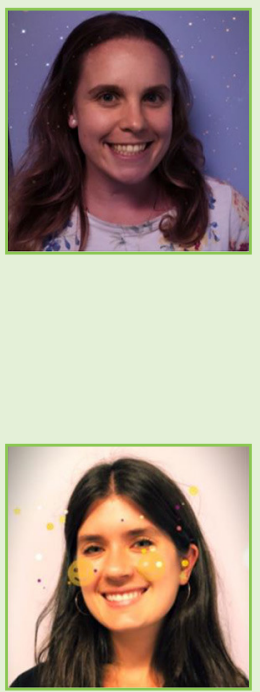

\section{AUTHORS}

\section{LUCÍA MAGIS-WEINBERG}

I am a doctor and scientist investigating how technology impacts the development of children and adolescents and their brains, particularly in countries in Latin America. I use technology all the time-to do my work, to run our projects in other countries, and to communicate with my family and friends that live far away-so I realize the power that comes with online interactions. Through my research, I want to help adolescents thrive in a world of accelerated technological change. *l.magisweinberg@aberkeley.edu

\section{ESTELLE L. BERGER}

I am a post-baccalaureate psychology student, and I explore the intersection of adolescent development, social context, and technology use. Through my research, I am continually inspired by young people's power to inspire and create meaningful change in the world. Outside of the lab, you can find me hiking, attempting the Sunday crossword puzzle, or taking care of my plants. 